\title{
A Review of Text Messaging (SMS) as a Communication Tool for Higher Education
}

\author{
Dr. Daragh Naughton \\ Limerick Institute of Technology \\ School of Applied Science, Engineering \& Technology \\ Department of Mechanical \& Automobile Engineering \\ Moylish, Limerick, Ireland
}

\begin{abstract}
Since 2011, The Limerick Institute of Technology (School of Applied Science Engineering \& Technology) has actively engaged in a course of research to determine if SMS can be used to (1) increase student's preparation for class, (2) increase their motivational levels towards learning and (3) to assist with memory retention. The purpose of this paper is to introduce the concept of the technology and to summarise the academic arguments that have been made both for and against the use of such technology for teaching and learning activities in higher education. A full quantitate and qualitative analysis of the research will take place in 2014 . The project forms part of a school wide Scholarship of Teaching \& Learning approach (SoTL). This paper will be of interest to academic managers, program managers, e-learning support staff, administrators and lecturers.
\end{abstract}

Keywords-SMS; text message; higher education; motivation

\section{INTRODUCTION}

Since 2011, the School of Applied Science, Engineering and Technology at the Limerick Institute of Technology has used SMS as a communication tool as part of its institute wide Scholarship towards Teaching and Learning (SoTL). Almost 10,000 text messages have been delivered to $1^{\text {st }}$ and $2^{\text {nd }}$ year mechanical engineering students in that period. The pilot scheme was designed to increase student's motivation and preparedness for class. Motivational texts were scheduled and delivered using a unique SMS portal. The following discussion presents the background to the research and should be of interest to educational managers and lecturers in the cognitive areas of science, engineering, information technology and math. A full statistical analysis of the results will be available publically in January of 2014 .

Supporting students at vulnerable points in their academic career has always presented challenges. The step-up in maturity required from post-primary to higher education can be difficult for students to manage. Reaching this generation irrespective of the maturity challenge also presents its own difficulties. Fortunately, the latest generation of undergraduates has grown up in a world of persuasive digital technology which has caused them to develop fundamentally different ways of thinking and processing information from their predecessors and teachers [1]. SMS offers the ability to communicate directly with the students in a personal manner and can assist with not only enhancing the first year learning environment [2] but with a raft of other directly related areas including (1) communication and administrative support [3],
(2) teaching and learning support [3] and (3) encouraging interactivity [4].

As a communication tool, SMS allows senders to transmit short messages of 160 alphanumeric characters to any suitable receiving device operating over the GSM network. The fact that children are growing up with wireless mobile technologies with positive outcomes in modern society is an indicator that SMS technologies should be embedded in the epistemologies of modern universities [5]. The potential success of any SMS education program is reinforced by the ever-growing popularity of mobile devices. In the UK alone, OFCOM reported that $96 \%$ of 15-24 age groups own GSM enabled devices [6] while a study at the University of Dundee found that $96 \%$ of students in their university owned a mobile phone [7]. Further research by Harley et al. reported that students were happy to receive pastoral support via SMS from university staff [8].

Use of SMS in education supports students to learn in "no fixed location or time" [9] and therefore the learning is facilitated at a time and location which suits the students (mobile devices have the capability to store and retrieve information). The learning aspect of SMS can operate on either a push model or a pull model [10]. In a push model, the teacher dictates which information is sent and at what time; the student is not afforded the opportunity to reply. Conversations are one way and are limited to motivational and preparatory elements of the lesson plan. The pull model is a closed loop system where students can reply, give answers and receive feedback. Other usages of SMS services include fill in the blanks, true false questions, multiple choice questions etc. [11]. The current research suggests that being accessible, contextualised and collaborated are the main appeal for mobile phones in learning [12]. The learning curve and familiarity for the periphery devices is also reduced given the overwhelming number of students who own and operate phones, therefore, mobile devices can be more easily integrated across the curriculum than desktops or SMARTTM boards [13]. Also, as these devices are convenient and provide an expedited learning experience in student appropriate locations.

\section{WhERE Is THE TEACHING \& LEARNING EVIDENCE?}

Evidence within the higher education sphere includes but is not limited to the following:

Evidence of SMS as a teaching aid in higher education: Wallace has used SMS successfully to teach business 
information systems development to undergraduates at the University of the West of England. He concluded that the simplicity of the technology made it viable and that it "encouraged good development practices" amongst the final year undergraduates [14]. Hagos successfully used SMS technology to promote on-going learning in the area of mathematics. The research concluded that SMS proved to be a valuable asset in focusing the students' attention towards the learning of mathematics even when the lecturer was late or absent from class [15]. So, a researcher at the Hong Kong Institute of Education developed a bespoke SMS texting service and used the system to increase participation amongst students on a Bachelor of Education degree program. Although the research lacked supporting data, it is an excellent example of the technical development required to integrate SMS into the Teaching Tutee Tool paradigm [3].

Evidence of SMS as a transitional support technology: Jones et al. used SMS as a support tool to aid the transition of post primary students to higher education. The research suggested that students reacted differently to the SMS service but that overall the advantages outweighed the disadvantages. Interestingly, Jones et al. found no evidence to suggest that students saw texting as in intrusion into their personal space [2].

Evidence of SMS as an encouraging communication tool: In a survey of 532 students, Leung found those students who used SMS the most were motivated by its convenience, lowcost and its utility for coordinating events. The research also found evidence to suggest that SMS helped students overcome shyness and an un-willingness to communicate in an educational setting [16].

Evidence of SMS as an advocacy service: Young et al. used SMS texting to provide an advocacy service for student nurses, occupational therapists and radiographers on clinical placement in the United Kingdom. The research found that the students and staff embraced the technology but concerns were raised about the uptake of the service. The research concluded that safeguards must be established to ensure inclusion of all (even those who do not own their own personal phones) [17].

Evidence of SMS as an administrative support tool: Nordin et al., albeit with a limited sample size, suggests that school administrators view the use of SMS as an appropriate communication tool for learner-teacher activities. $80 \%$ of those administrators surveyed responded positively to SMS as a teaching and learning assistive protocol [18].

Example of SMS as a tool for encouraging interactivity: Researchers from Trinity College Dublin successfully used SMS to successfully increase the interactivity of higher education students drawn from undergraduate and postgraduate sample pools. The "PLS TXT UR Thoughts" project concluded that SMS led to a more active learning environment, a greater provision of feedback for lecturers and increased student interest and motivation.

\section{AdVANTAGES OF SMS For HighER EDUCATION}

Advantages of SMS technology within the educational context include:

- Low cost of operation from an academic institution's perspective as the technology is owned by the students [6].
- Instant communication and real time feedback is possible [19].

- Transactional distances and geographical barriers are no longer constraints [20].

Students readily accept the use of SMS as a communication device and research has indicated that communicating on such a personal level helps to foster a sense of community and gives a sense of "belonging to the university" [21] [8]. Jones et al. produced a body of research which indicated that SMS usage makes a valuable contribution towards the teacher as a "facilitator" or "broker" and can help to motivate participation in appropriate activities [2]. Overall, it would appear that the advantages of using SMS for supporting higher education outweigh the disadvantages.

\section{DisAdVAntages OF SMS For Higher EdUCATION}

The disadvantages of SMS within the learning environment have been extensively reviewed by Jones et al. [2]. Issues can arise over the ownership and control of the periphery device. Despite the teachers best intentions, intrusions into class time can detract from the teachers overall control of the class and the students focus. Mifsud has termed this the "intruder" effect [19]. Also, mobile phones tend to have small screens and the length of the messages is limited to 160 characters. This makes it difficult to communicate as effectively compared to conventional devices (e-mail etc.). Other researchers have raised concerns about the cost of such a program although the cost issue has failed to make a strong argument against the use of the technology when comparisons are drawn against other technological devices such as student response systems and PDA's etc. [4].

Sharples has called for caution and suggests that the introduction of mobile learning into an academic environment is not a panacea as it can bring problems as well as solutions; in particular the perception that young people may see the use of SMS for formal learning as an attempt to colonise and intrude on social spaces [20]. Markett et al. found that the interaction between face-to-face teaching methods and challenges set by SMS protocols became blurred and provided an unwelcome distraction [4]. He concluded that this may make the transition to higher education more challenging for the user. Horstmanshof has concluded that the additional workload in establishing a new communication media may prove difficult for existing teaching staff [21]. He also concluded that students may become addicted to the overdependency that SMS communication may foster; and that this in turn may hamper the "natural development of more selfregulatory strategies". Noble has concluded that the use of such technology can turn universities into "digital diploma mills" and reminds the reader that education is a process that necessarily entails an interpersonal (not merely interactive) relationship between people [22].

\section{CONCLUSIONS}

Although SMS has some detractors, there is no doubt that it can have significant benefits for educators and education management. Anecdotal evidence from the research currently being conducted at the Limerick Institute of Technology suggests that students associate similar gratification elements of SMS usage to other communication media such as TV or the internet. Significantly, students have also indicated that they do not consider SMS as an intrusion into their personal 
space. Some interesting topics have been raised by the current research; such as the ability of SMS to function equally well in classrooms where varying contradictory educational paradigms exist, in particular both behaviorism and constructivism. When available and fully analysed, the results of the current research and its limitations will be made public in keeping with The Limerick Institute of Technology's commitment to the SoTL framework.

\section{ACKNOWLEDGMENT}

The author wishes to express gratitude to the Limerick Institute of Technology Development Office for facilitating this course of research.

\section{REFERENCES}

[1] D. O. J. Oblinger, "Educating the next generation," 2005. [Online]. Available: www.educause.edu/books/educatingthenextgeneration/5989.

[2] G. E. G. R. A. Jones, "How can mobile SMS support and enhance a first year undergraduate learning environment?," Research in learning technology, vol. 17, no. 3, pp. 201-218, 2009.

[3] S. So, "The development of a SMS based teaching and learning system," Journal of Educational Technology Development and Exchange, vol. 2, no. 1, pp. 113-124, 2009.

[4] C. S. I. W. S. T. B. Markett, "Using short message service to encourage interactivity in the classroom," Computers and Education, vol. 46, pp. 280-293, 2006.

[5] I. Y. S. L. C. Tsai, "Exploring the course development model for the mobile learning context: a preliminary study," Taiwan, 2005.

[6] OFCOM, "The consumer experience research report," 2007. [Online]. Available: www.ofcom.org.uk/research/tce/ce07/researcho7.pdf.

[7] University of Dundee, "Mobile Communications Survey," 2006. [Online]. Available: www.dundee.ac.uk/elecengyphics/mobilesurveyresults.php.

[8] D. W. D. P. S. W. P. Harley, "Using texting to support students' transition to university," Innovations in Education and Teaching, vol. 44, no. 3, pp. 229-241, 2007.

[9] Kinshunk., "Adaptive mobile learning technologies," 2003. [Online]. Available: www.kcweb.org.uk/weblibrary/M-learning.pdf. [Accessed 12 01 2012].

[10] I. K. A. K. D. U. H. Yengin, "Is SMS still alive for education: Analysis of Educational potentials of SMS technology?," Procedia Computer Science, vol. 3, pp. 1439-1445, 2011.
[11] TxtTools, "SMS Text Messaging for Education," 2008. [Online]. Available: www.texttools.co.uk.

[12] S. Geddes, "Mobile learning in the 21st century; Benefits for Learners," The Knowledge Tree, vol. 6, 2006.

[13] D. H. S. Mosoley, "Ways forward with ICT effective pedagogy using information and communications technology for literacy and numeracy in primary schools," Newcastle, 1999.

[14] C. Wallace, "Teaching information systems development with SMS," in The 9th Java and the Internet Computing Curriculum Conference (JICC9), London Metropolitan University, London , 2005.

[15] L. Hagos, "Enhancing teaching and learning through SMS-mediated lectures in mathematics," in Hybrid learning: A new frontier ICHL, Hong Kong, 2008.

[16] L. Leung, "Unwillingness-to-communicate and college student's motives in SMS mobile messaging," Telematics and Informatics, vol. 24, pp. 115-129, 2007

[17] P. M. E. G. G. R. R. S. R. C. M. F.-P. M. Young, "Help is just a text away: The use of short message service texting to provide an additional means of support for health care students during practice placements," Nurse Education Today, vol. 30, pp. 118-123, 2010.

[18] M. H. I. Y. N. E. M. Nordin, "The mobile learning environment for the in-service school adminstrators," Procedia social and behavioural sciences, vol. 7, no. C, pp. 671-679, 2010.

[19] J. Attewell, "Mobile Technologies and Learning; a technological update and m-learning project summary," Learning and Skills Development Agency, London, UK, 2005.

[20] P. C. A. Gorsky, "A critical analysis of transactional distance theory," The Quarterly Review of Distance Education, vol. 6, no. 1, pp. 1-11, 2005.

[21] L. Horstmanshof, "Using SMS as a way of providing connection and communication for first year students," in Beyond the comfort zone; Proceedings of the the 21st ASCILITE conference., Perth, Western Australia, 2004.

[22] L. Mifsud, "Alternative learning areanas-pedagogical challenges to mobile learning in education," in IEEE international workshop on wireless and mobile technologies in Sweden, Vaxjo, Sewdwn, 2008.

[23] M. Sharples, "Big issues in mobil learning," University of Nottingham, Learning Sciences Research Institute, Nottingham, UK, 2007.

[24] D. Noble, "Rehersal for the revolution," in Theoretical principles of distance education, Oxon, Routledge, 2002, pp. 22-38. 